\title{
EXPERIMENTAL APPEALS TO INTUITION
}

Renia Gasparatou University of Patras gasparat@upatras.gr

SUMMARY: Today, experimental philosophers challenge traditional appeals to intuition; they empirically collect folk intuitions and then use their findings to attack philosophers' intuitions. However this movement is not uniform. Radical experimentalists criticize the use of intuitions in philosophy altogether and they have been mostly attacked. Contrariwise, moderate experimentalists imply that laypersons' intuitions are somehow relevant to philosophical problems. Sometimes they even use folk intuitions in order to advance theoretical theses. In this paper I will try to challenge the so-called moderate experimental attempts to rely on intuition in order to promote philosophical theses.

KEY WORDS: epistemology, introspection, conceptual analysis, experimental philosophy

RESUMEN: Hoy en día, los filósofos experimentales ponen en duda la tradición de apelar a la intuición; coleccionan intuiciones empíricas populares y después utilizan sus descubrimientos para atacar las intuiciones de los filósofos. Sin embargo, esta estrategia no es uniforme. Los experimentalistas radicales critican cualquier uso de intuiciones en filosofía y han sido objeto de los mayores ataques. A diferencia de ellos, los experimentalistas moderados sugieren que las intuiciones del vulgo son de alguna manera pertinentes en los problemas filosóficos. Algunas veces incluso usan intuiciones populares para defender tesis teóricas. En este trabajo pretendo poner en duda los intentos de los llamados experimentalistas moderados de apelar a intuiciones para promover tesis filosóficas.

PALABRAS CLAVE: epistemología, introspección, análisis conceptual, filosofía experimental

\section{Introduction}

Philosophers have often appealed to their own intuitions and used them to reflect on philosophical problems. Philosophers' intuitions are supposed to represent any competent speakers' intuitive response and thus illustrate the conceptual norms of the community. Nowadays, experimental philosophy challenges such traditional appeals to intuition. Experimental philosophers (thereafter experimentalists) ask real folk what they think about this and that, and show that laypersons' intuitions vary from those reported by philosophers. Philosophical intuitions then do not represent the pre-theoretical intuitions of the community. This method has been criticized before. Experimental philosophy however, provides empirical evidence that the traditional appeal cannot deliver the community's intuitions. 
Moreover, some experimentalists suggest that layperson's intuitions are closely related to philosophical problems; they even imply that those intuitions advance theoretical theses. In this paper I will try to argue that experimental philosophy cannot rely on pretheoretical intuition to support philosophical theories.

First I will summarize the rationale behind traditional (or armchair) appeals to intuition. Then, I will outline some experimental studies, which I will use as examples of two different tensions within experimental philosophy. ${ }^{1}$ All collect folk intuitions. Yet,

(a) some experiment in order to criticize any use of intuitions in philosophy. They have been recently called radical experimentalists and they have been mostly attacked (Liao 2008). I will suggest that the radical experimentalists' view is coherent; they show the problems one faces when depending on intuition as evidence.

(b) others, the so-called moderate experimentalists (Liao 2008), seem to believe commonsensical intuitions are relevant to philosophy and they even use them in order to promote theoretical theses. I will try to show that moderate experimentalists' agenda is incoherent. Their experiments demonstrate how un-philosophical and untrustworthy commonsensical intuitions are. Yet, they use pretheoretical intuitions to support philosophical theses. They confront the metaphilosophical view that holds the traditional appeal to intuition. Still, they depend on intuitions in the way traditionalists have. Such a practice cannot be justified coherently within their overall view.

\section{Traditional Analytic Philosophy}

Traditional Analytic Philosophy (thereafter $T A P$ ) suggests that philosophy is a sui generis conceptual investigation. Traditional analytics (or traditionalists) claim they uncover the conceptual rules and presuppositions of the community.

There is a conceptual background that is common for all humans who speak the same language or share the same culture at a certain

${ }^{1}$ I will distinguish between radical experimentalists and moderate experimentalists, following S.M. Liao (2008). This in fact, is rather a way of classifying experimental studies into two different groups. For we sometimes see traces of radical as well as moderate experimentalism in the same philosopher at different studies. Yet, many experimentalists start out as radicals, just criticizing traditional appeals to intuition (see section 3.1), and gradually become moderate while trying to justify the relevance of their method with philosophy (see section 3.2 ). 
historical time. Within this form of life, to use a Wittgensteinian

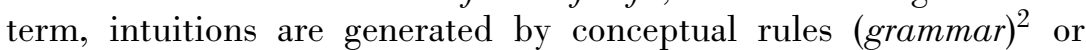
background certainties (common sense) ${ }^{3}$ and will thus provide us with epistemic standards. Philosophy clarifies our understanding; it describes conceptual rules. It is normative and independent from the sciences. Such a view holds the autonomy of philosophy as a discipline and it allows for its special kind of authority (Gutting 1998; Bealer 1998). It also formulates the method philosophers should employ. The philosopher focuses on some philosophically interesting concept and analyses it. Her mastering of language is (above) average and thus her intuitions on the use of a concept are as good (or even better) than anyone's. Moreover, she is better trained in performing conceptual analysis than an average person. This view is, explicitly or implicitly, suggested by many, such as Barry Stroud (2000), George Bealer (1996, 1998, 2004), Ernest Sosa (2007), Antti Kaupinnen (2007).

On many occasions, traditionalists rely on intuition in order to dissolve, rather than address, philosophical problems. The mental note of our conceptual rules and commonsensical dispositions is supposed to dismantle certain philosophical problems. Certain philosophical problems or theories abuse those rules and dispositions and are thus nonsensical. This is how Ludwig Wittgenstein or J.L. Austin used ordinary language or how P.M.S. Hacker (Bennett and Hacker 2003, pp. 72-73) and Frank Jackson (1982, p. 198; 1998, pp. 31-32) today utilize their intuitions. ${ }^{4}$

\section{Experimental Philosophy}

Recently, Experimental Philosophy (thereafter X $\Phi$ ) empirically challenges TAP's appeal to intuition. Experimental philosophers design questionnaires, conduct empirical studies and compile statistical results. Their questionnaires describe some hypothetical story, just like thought experiments do. But here ordinary people, not the philosophers themselves, give the answer. The folk are asked about knowledge, free will, intentional action, etc. Experimentalists record their answers; they comment on whether the folk agree with the intuitions of the philosopher and they hypothesize on what factors influence intuitive responses. Let's look at some studies.

${ }^{2}$ See for example Bennett and Hacker 2003.

${ }^{3}$ See for example Jackson 1982 and 1998.

${ }^{4}$ See also R. Gasparatou 2009 and 2010. 
Jonathan Weinberg, Shaun Nichols and Stephen Stich (2001) study the reaction of subjects coming from different cultural and economic environment to Gettier-like stories (Gettier 2000). They found out that, although the socio-economic background didn't make any difference, cultural background gave rise to different intuitions. Subjects were requested to consider the following story:

Bob has a friend Jill, who has driven a Buick for many years. Bob therefore thinks that Jill drives an American car. He is not aware, however, that her Buick has recently been stolen, and he is also not aware that Jill has replaced it with a Pontiac, which is a different kind of American car. Does Bob really know that Jill drives an American car, or does he only believe it? (Weinberg et al. 2001, p. 440)

Subjects were asked whether Bob (a) really knows or (b) only believes. It turned out that 74 percent of western subjects would agree with Gettier that (b) Bob "only believes" something when faced with a Gettier counter-example, while 56 percent of Asians and 61 percent of Indians think (a) he "really knows".

According to the philosophers conducting the experiments above, the results provide evidence that different communities hold different epistemic standards. The same conclusion is verified by a different experiment testing the intuitions of Westerner and Asian nationals regarding the reference of proper names. Nichols, Stich and Weinberg (2003) described a story Saul Kripke (1996) first came up with: A man named Schmitt discovers the incompleteness of arithmetic but then he gets killed. Another man named Gödel steals his manuscript and claims credit for the work. Subjects were asked: "when one uses the name 'Gödel', is he talking about: (A) the person who really discovered the incompleteness of arithmetic or (B) the person who got hold of the manuscript and claimed credit for the work?" It turned out that Westerners were more likely than Asians to answer (A) and give causal-historical responses.

Both the Gödel-experiment and the Bob-experiment show that different cultural groups report different intuitions. The stories described were modeled on some of the most influential thought experiments in analytic epistemology; yet they elicited culturally variable intuitions. Both studies imply that it is wrong for philosophers to consider their own intuitions about knowledge or reference universal and draw general conclusions out of them (Nichols et al. 2003, pp. 17-20; Weinberg et al. 2001, pp. 450-458). 
Studies along similar lines are being performed every day now, suggesting that intuitions are not as unanimous as philosophers have taken them to be. In fact, many factors interfere with any such appeal. Nichols and Knobe (2007) suggest that the rhetoric of the thought experiment influences our emotions and thus our intuitions. Nichols, Stich and Weinberg (2003) argue that intuitions differ depending on how many philosophy courses one has attended. Stacey Swain, Joshua Alexander, and Jonathan Weinberg (2006) show that responses vary according to whether one has considered other thought experiments first.

In another study, Eddy Nahmias, Stephen Morris, Thomas Nadelhoffer and Jason Turner (2008) challenge the claim that incompatibilism is intuitive and discuss the philosophical significance of their findings. Incompatibilists believe free will is impossible if determinism is true, and they often claim that this view is supported by ordinary intuitions (Strawson 1986; Kane 1999; Ekstrom 2002). In order to examine such a claim, Nahmias et al. gave the participants the following story:

Imagine that in the next century we discover all the laws of nature, and we build a supercomputer which can deduce from these laws of nature and from the current state of everything in the world exactly what will be happening in the world at any future time. It can look at everything about the way the world is and predict everything about how it will be with 100 percent accuracy. Suppose that such a supercomputer existed, and it looks at the state of the universe at a certain time on March 25, 2150 A.D., twenty years before Jeremy Hall is born. The computer then deduces from this information and the laws of nature that Jeremy will definitely rob Fidelity Bank at 6:00 pm on January $26 \mathrm{~h}, 2195$. As always, the supercomputer's prediction is correct; Jeremy robs Fidelity Bank at 6:00 pm on January 26 h, 2195. (Nahmias et al. 2008, p. 87)

Do you think that, when Jeremy robs the bank, he acts of his own free will?

A significant majority (76 percent) of participants judged that Jeremy acts of his own free will. To test for the possibility that participants were influenced by the negative nature of the action, Nahmias et al. replaced Jeremy's robbing the bank with a positive action (saving a child) for another set of participants and with a neutral action (going jogging) for a third set. The moral nature of the action had no significant effect on the participants responses: 68 percent judged 
that Jeremy saves the child of his own free will, and 79 percent judged that he goes jogging of his own free will.

They also conducted the same experiment asking a different question: "is Jeremy blameworthy for robbing the bank? (yes/no) And is Jeremy praiseworthy for saving a child? (yes/no)." In both cases people ascribed moral responsibility to Jeremy: 83 percent said he is blameworthy for robbing the bank, and 88 percent said he is praiseworthy for saving the child. The same results were verified by follow-up studies.

Nahmias et al. suggest that the folk intuitions regarding free will and moral responsibility, which the Jeremy-thought experiments triggered, reveal that the folk (a) think that free will and responsibility are compatible with determinism. Moreover they (b) dispute philosophers' claim that incompatibilism is intuitive, and (c) provide an evidential advantage to compatibilistic philosophical theories. In the last section of the paper I aim to challenge (b) and (c). But first let me comment on the first experimental studies outlined above.

\subsection{Radical Experimentalism and Skepticism about Intuition}

At least some part of the $\mathrm{X} \Phi$ movement aims at criticizing TAP's method and its underlying assumptions. Their experiments show how diverse our intuitions are and how many factors interfere with such an appeal; for example, emotions, prior education, the rhetoric of the story suggested, etc. It seems then that intuitions do not arise solely from conceptual rules. Moreover they indicate that, given all the factors that interfere with any appeal to intuition, people will never report the same intuition. Different cultural backgrounds, intellectual habits, knowledge, etc., generate different intuitions. It becomes clear that philosophers' intuitions do not stand for any unanimous presumptions, dispositions or rules. Moreover, if different groups or communities report different intuitions, their epistemic principles will probably vary as well. Intuition analysis has no way of telling us which, if any of them, has epistemic privilege.

However, all these objections have been expressed long before $\mathrm{X} \Phi$, and some times from philosophical armchairs. It has been suggested that conceptual rules are not independent from empirical knowledge or beliefs; therefore intuitions do not come from the community's purely conceptual dispositions and norms; people's beliefs generate them. Those beliefs may be widespread; they may arise from tacit 
theories. Yet, this does not prevent them from being wrong and/or open to revision or elimination. ${ }^{5}$

On many an occasion other scientists' empirical studies have been cited to supplement this line of criticism. Many psychological experiments have shown that lots of factors influence our intuitions and that intuition cannot offer the detached understanding traditionalists connect it with. ${ }^{6}$ Many statistical surveys show that our intuitive judgments are wrong most of the time (Bishop and Trout 2005). On the face of all these attacks, one may wonder what new experimentalists bring against TAP's appeal to intuition.

Experimental philosophers no longer rely on other scientists' studies. This allows $\mathrm{X} \Phi$ to examine intuitions about concepts of high philosophical importance. They show how diverse and unreliable our intuition is when confronted with philosophical questions. I think this is what the Gettier-case (Weinberg et al. 2001) and the Kripkecase (Nichols et al. 2003) studies aim at. They want to show that one cannot draw any general theory about knowledge or reference based solely on intuition. Those experiments rely on Stich's hypothesis that reflective equilibrium cannot help when forming philosophical theories, since different communities may have very different epistemic standards (Stich 1990, 1998). Some thought Stich's suggestion was unrealistic (Pollock and Cruz 1999, p. 150). Studies however provide strong evidence that different communities do in fact have different epistemic norms.

Experimental studies criticizing TAP are the ones that have been challenged the most. They are seen as a threat to any appeal to intuition; and consequently as a threat to philosophy itself as traditionally conducted. Thus, Sosa (2007) claims experimental techniques cannot explain why subjects disagree, nor can they assure that the folk get the stories right; Kauppinen (2007) and Jackman (2009) suggests that philosophy should analyze the robust intuitions of the philosophers rather than the surface intuitions of the folk; Williamson (2004) and Sosa $(2006,2008)$ argue that once we abandon philosophers' hope-

\footnotetext{
${ }^{5}$ Such an objection lies behind all arguments against a priori or logical truths, deep linguistic intuitions, conceptual schemes, transcendental arguments and so forth and, accordingly, against any sharp distinction between the conceptual and the empirical (or philosophy and science), which the traditionalists imply. See for example: Quine 1953; Putnam 1962; Fodor 1964; Haack 1974; Kitcher 1983; Churchland 1986; Cummins 1998; Dennett 1991, pp. 399-400. See also Dennett 2006, pp. 103 126; Bishop and Trout 2005, Williamson 2004; Stich 1990 and 1998.

${ }^{6}$ See for example Gopnik and Schwitzgebel 1998; Cummins 1998; Ramsey 1998, Haidt, Koller and Dias 1993; Howard and. Dawes 1976.
} 
lessly demanding operational standard for evidence, we will see that we can trust intuition, just like we trust perception or introspection as a corrigible evidence. Moreover, Liao (2008) proposes that even radical experimentalists rely on intuition for their very criticism. However, none of these arguments stands against the radical experimentalists' main point. For none suggests that a theory can be proven right just by appealing to our pre-theoretical intuitions.

Radical experimentalists only show the defects of TAP's method. They provide evidence against the suggestion that we all share similar dispositions and norms. Moreover they challenge the claim that the philosopher can represent the average language user. Hence they propose that philosophy cannot rely on intuition. This line of criticism has been suggested before. Empirical support makes it slightly more aggressive. Still, if the so-called radical experimentalists are interpreted as providing a critical comment against traditionalists' method, they are not that radical after all. They just build on a coherent criticism. Philosophizing cannot rely solely on intuition. In the next section, I will try to show that it is actually the methods of the moderate experimentalists that face serious problems.

\subsection{Moderate Experimentalists' Appeal to Intuition}

Experimentalists confront the armchair method; yet many share TAP's underlying assumption that philosophy relates to common sense. In their view, the intuitive responses of the folk can challenge or support philosophical theses. Thus, they often imply that a theory, which accords with laypersons' intuitions, has a theoretical advantage over opposing ones.

For example, Nahmias, Morris, Nadelhoffer and Turner (2005):

agree with Jackson (1998) that the fundamental issue in the free will debate should be "whether free action according to our ordinary conception, or something suitably close to our ordinary conception, exists and is compatible with determinism" and that to identify our ordinary conception we must "appeal to what seems to us most obvious and central about free action [...] as revealed by our intuitions about possible cases". (Jackson 1998, p. 31; Nahmias et al. 2005, p. 564)

Philosophy is attached with common sense. Philosophers talk about notions that trouble ordinary people as well; their analyses can only help insofar as they relate to ordinary notions. The same argument 
can be found in many $\mathrm{X} \Phi$ papers. ${ }^{7}$ In "An Experimental Philosophy Manifesto", Knobe and Nichols (2008a) defend the philosophical importance of $\mathrm{X} \Phi$ using the same argument. They suggest that philosophy (or at least some of its branches, like epistemology) is related to commonsensical intuitions since many philosophical problems arise from common sense.

Indeed, for many standard philosophical problems [...] if it weren't for the commonsense intuitions, there wouldn't be a felt philosophical problem. The problem of moral responsibility for example $[\ldots]$ arises because people think of themselves as morally responsible, and it seems at odds with other important and plausible world views. (Knobe and Nichols 2008a, pp. 8-9)

Common sense and its contradicting dispositions make an issue feel like a problem. This is why a philosophical theory should take ordinary intuitions into account. Free will and moral responsibility seem to be clear examples that philosophical worries arise because common sense faces certain contradictions.

This claim, however, is not supported by their experiments. In their studies concerning free will and moral responsibility, we see the folk not feeling the problem at all. In the Jeremy experiment above, the folk think Jeremy acts on his own free will and that he is responsible for stealing a bank/ saving a child/ going jogging, even when all of his actions are subject to deterministic laws and have been predicted by the super computer before he was born. The majority of laypersons do not seem to recognize any contradiction between a fully deterministic world and Jeremy's free will and responsibility. It seems then that the problem of free will or moral responsibility does not arise "because people think of themselves as morally responsible, and it seems at odds with other important and plausible world views" (Knobe and Nichols 2008a, p. 9). To the majority of the folk, their being responsible for their actions is not at odds with other views about how the world works. The experiment with Jeremy is only one among many Nahmias et al. (2005) used to show that free will is in fact not a felt philosophical problem at all. Hence Nahmias et al. entail that compatibilism is intuitive.

When we appeal to folk intuitions about possible cases, like Jackson, Knobe and Nichols, or Nahmias et al. invite us to do, we end

${ }^{7}$ See for example, Nadelhoffer and Nahmias 2007; Alexander and Weinberg 2007; Turner and Nahmias 2006; Nahmias 2006; Knobe 2003; Nichols 2004. 
up with no felt philosophical problems. It is rather philosophers who recognize the problems. At some level then, philosophers and the folk do use moral responsibility, free will, etc., differently. The relation between philosophical problems and folk intuitions may not be as close as either moderate experimentalists or traditionalists believe.

Experimentalists can bypass the problem. Besides, many have suggested that philosophy should only be interested in philosophers' intuitions since they are better trained in introspection than the folk (Kaupinnen 2007, Stroud 2000). “An Experimental Philosophy Manifesto" replies that, even if this were true, it should not defer us from conducting experiments. In fact, philosophical experiments will help understand how philosophers' intuitions differ from those carried by ordinary people and, most importantly, why:

We would love to know about the ways in which philosophers differ from ordinary folks, and it seems to us the best way to find out would be to run some experiments. [...] Furthermore even if we discover important differences between the philosophers and the folk, it would hardly follow that the data from the folk are irrelevant. Rather the whole pattern of the data might tell us something important about the ultimate source of the philosophical problems. (Knobe and Nichols 2008a, p. 10)

Experimental techniques determine whether philosophers' intuitions are different from those of laypersons. Such studies might even clarify the source of philosophical problems. The implication here is that philosophers have peculiar reasoning patterns, which create the philosophical problems. Although philosophers make less reasoning mistakes, "the folk are less likely to have their intuitions biased by extensive philosophical training and theoretical affiliations" (Knobe and Nichols 2008a, p. 10). It seems then that philosophical training and intellectual habits create the philosophical problems.

If the philosophical peculiarities create the problems though, then those problems are not as closely related to common sense as suggested above. Of course, we can go on investigating the differences between commonsensical intuitions and those held by philosophers just for the sake of it. We can try to find some kind of evidence that philosophers have actually created the problem. However, even if we somehow prove that philosophers' reasoning strategies or theoretically biased intuitions are the source of philosophical problems, this does not mean that philosophers are wrong in creating them. Their training may help them see aspects of reality that laypersons do not. 
Indeed, many philosophers have suggested that folk conceptions should be critically examined. ${ }^{8}$ Some of our beliefs and intuitions may even need revision or elimination. Philosophy should test folk intuitions rather than rely on them. Again, Knobe and Nichols propose that, in order to test or revise folk intuitions one should get to know those intuitions first (2008a, p. 10). Many experimentalists suggest the same:

Even if "free will" is a technical concept, it will have to be at least constrained by the non-technical concepts and practices of responsibility attribution if it is to do the work the philosophical community has set for it $[\ldots]$. These moves suggest that certain theories of free will and moral responsibility may require us to revise some, but not all, of our current concepts, beliefs, and practices about freedom and responsibility [...]. But in order to know whether a particular theory demands revision (or even elimination) of our concepts, beliefs, or practices, we have to know what these are. (Nahmias et al. 2005, p. 577; italics are mine.)

So even if we conclude that a certain concept or belief of ours needs revision or elimination, we have to know what exactly the folk intuit and then revise it. However, it is far from obvious that we actually need to write down all our intuitions in order to know exactly what we need to abandon in case some revision in our belief system is required. Revision of beliefs does not seem to work that way. One does not have to know their dispositions in order to alter them. Surveys might not actually be needed then. But then, again, one can choose to do the groundwork and register the community's intuitions anyway.

So far, experimentalists suggest empirical research is useful. It could help us realize our beliefs or find the source of philosophical problems. Yet, none of these claims entails that those intuitions can help answer those problems. In fact, experimentalists claim they accept that laypersons' beliefs may require modification. Folk intuitions cannot determine whether a theory is correct.

Despite their cautious remarks though, some clearly suggest that if a theory accords with common sense, it has a theoretical advantage. For example, according to Nahmias et al. 2008 (the example with Jeremy and the super-computer), people seem to believe in some form of compatibilism. This implies that since compatibilism

${ }^{8}$ See, for example, Churchland 1989. 
is intuitive it is a plausible theory: "a theory of free will that accords with those intuitions relevant to things we care about, such as ascriptions of moral responsibility, has, all else being equal, a theoretical advantage over a theory that demands revision or elimination of such intuitions" (Nahmias et al. 2008, p. 85). A theory that has commonsensical intuitions on its side then has a theoretical advantage. At the very least: "if a philosophical theory does turn out to be privileged by the endorsement of the folk, that would seem to position the burden of proof on the shoulders of those who argue contrary to folk intuitions" (Nahmias et al. 2005, p. 564). When a theory accords with laypersons' intuitions, it is privileged. The burden of proof is on the theory that contradicts common sense.

Many support the view that theories siding with common sense have some kind of advantage over other theories. Such an implication underlies their practice. Studies discussing free will (Nahmias et al. 2005, 2008) probably started in order to confront the armchair intuitions of incompatibilists philosophers like Robert Kane (1999), Galen Strawson (1986), etc. But now the list is growing longer and longer. And different studies show alternative theses to be supported by common sense. Experiments are interpreted alternatively as either allying with compatibilism (Turner and Nahmias 2006, Nahmias 2006) or some forms of incompatibilism (Nichols 2004). Thus Nichols (2004) suggests that the folk supports a libertarian notion of free will that is incompatible with determinism; Turner and Nahmias (2006) challenge Nichols' interpretation and Nahmias (2006) concludes that only certain kinds of reductionistic descriptions of decision-making are incompatible with free will, whereas the folk does not really pick determinism as a threat to free will and moral responsibility. Nahmias uses both Nichols studies, as well as some of its own, to suggest that the folk may see reductionism as incompatible with free will, but they do not consider that determinism is incompatible with free will. He bravely concludes: "Well, what else would you expect from a compatibilist? I'm just trying to sell my own intuitions like any good philosopher (though I have at least supplemented my claims with some empirical work on pre-philosophical intuitions)" (Nahmias 2006, p. 234). The free will debate, as conducted within the community of experimental philosophy, shows that experimental methods are used in order to promote different philosophical theories. It is not my point here to enter the free will debate but rather to comment on how experimentalists use intuitions. Of course, they do not claim that such theories are true or correct because common 
sense allies with them (Nahmias et al. 2008, p. 97). Yet, those theories are expected to have some sort of advantage over alternative ones. Some experimentalists are cautious enough as to suggest that traditionalists first put the burden of proof primarily on those confronting common sense (Nahmias et al. 2005, p. 577). Yet moderate experimentalists never take issue with this suggestion. Quite on the contrary, most of the experimental endeavor these days implies that philosophical theories that accord with common sense are privileged. Folk intuitions then carry a strong argumentation value. Such a claim is still highly problematic for the experimentalist too. ${ }^{9}$

Many have blamed traditionalists for stretching their own commonsensical or grammatical intuitions to fit their philosophical theories. Now, experimentalists also impose philosophical theories on common sense. In some cases, they ask for ordinary intuitions while describing highly extraordinary cases. The experiment with Jeremy, for example, describes an extraordinary, science-fiction story about which we cannot have any commonsensical intuitions. Normally, the situation itself is supposed to guide us. However, it is very difficult to intuitively prescribe whether Jeremy robs the bank of his own free will when the context is out of the ordinary; or when our beliefs are being questioned. One cannot appeal to common sense while challenging it. $^{10}$

The peculiarity of the thought experiment described is, however, only part of the problem. After all, on many occasions their stories are not that extraordinary. Still, the moment the folk are asked to vote for or against philosophical theories, experimentalists impose theories on common sense. ${ }^{11}$ And this seems to happen in all X $\Phi$ 's papers. Experimentalists first lay down a map of the philosophical theories suggested on an issue, and then they run their experiments trying to figure out which theory best accords with common sense. Are the folk compatibilists or incompatibilists? And if incompatibilists, are they libertarians or hard determinists? Is determinism considered a threat to free will or is it reductionism instead? Philosophical discussions about free will may be generated from the ordinary notion. Regardless, compatibilism, incompatibilism, determin-

${ }^{9}$ See also Gasparatou 2008.

${ }^{10}$ See Wittgenstein 1958, § 142; Austin 1961, p. 67. Although from a different perspective, Fodor 1964 and Dennett 1991, pp. 190-191, also agree.

${ }^{11}$ Surveys concerning the reference of proper names above (Nichols et al. 2003) make the same mistake (see Jackman 2009, section 6); yet they are mostly used to criticise any general theory about reference, which depends on intuitive analyses, rather than promote one of them. 
ism, reductionism, etc., are technical philosophical theories. Even if philosophical problems were related to common sense, this would not entail that common sense can vote for or against philosophical doctrines. Folk intuitions might be more diverse, more perplexed or more incoherent than any of these theories. And, from what philosophical experiments entail, they probably are.

As Nahmias (2006, p. 234) humorously admits, philosophers have always tried to sell their own intuitions as everyone's. Long discussions of TAP' methodology suggest that traditionalists have always had great difficulty bypassing this line of criticism. And now things are far worse for $\mathrm{X} \Phi$.

Some traditionalists claimed that pre-theoretical intuitions could only help if one wants to dismantle a philosophical problem. J.L. Austin, for example, whom some experimentalists cite as a precursor of their method (Alexander and Weinberg 2007, p. 18), argues that one cannot appeal to ordinary intuitions when the situation is extraordinary (Austin 1961, p. 67). And he implies that philosophy itself is extraordinary insomuch as it seeks for general explanations. Thus he mostly appeals to ordinary intuitions in an attempt to "dismantle" philosophical doctrines "before (they) get off the ground" (Austin 1964, p. 142). So far, experimentalists do not suggest they aim at the dissolution of philosophical problems. Contrariwise, they try to promote philosophical theories using common sense. ${ }^{12}$

Yet, people can be wrong. In fact folk intuitions have been wrong many times. TAP tried to suggest that their intuitions are generated by the normative use of concepts; they argued this conceptual level is somehow more basic than tacit theories or other random factors that may interfere with our every day claims. They appealed to informed or reflective intuitions thinking they reveal the community's epistemic norms. Experimentalists, on the contrary, accept (and have even offered evidence to show) that intuitions are not solely generated by norms; intuitions come from tacit beliefs, emotions, intellectual habits, etc. None of the above is suggested as being reliable. But then one cannot justify the use of intuitions in the place of solid arguments; neither can they rely on intuitions in order to promote philosophical theories. For everyone's intuitions can be biased from all those factors.

Experimentalists have shown how flexible intuitions are. The mere consideration of a previous thought experiment can change the intuition we report when considering another (Swain et al. 2006). Dif-

\footnotetext{
${ }^{12}$ See also Gasparatou 2010.
} 
ferent experiments trigger different intuitions on the same subject (Nahmias 2006). Emotions also influence intuitions. Folk intuitions then are very easy to manipulate. And if they are so flexible, then common sense cannot support any general theory; we can just manipulate it and deliver whatever result we need. What is more, the same studies can be interpreted differently. ${ }^{13}$

On top of this, lies an additional problem: the folk disagree. Experimentalists say that the issue of epistemic criterion does not concern them any more than it would some other philosopher (Knobe and Nichols 2008, p. 10). Yet, if this is a problem for traditionalists, it is even more worrying for experimentalists. Traditionalists have claimed that intuitions rely on conceptual norms and cannot vary much; that everyone would agree in ideal circumstances (that is, if thinking straight). Intuitions collected by philosophical reflection, supposedly arose from conceptual norms and were thus undisputed. Experimentalists, however, have opened Pandora's box and such a claim can no longer fly. For all experiments show strong differences of opinion. They have moreover documented that different cultural or educational background, previous knowledge, habits, emotions, etc., influence our intuitions. Intuitions do not come from conceptual rules alone. Intuitions vary. So, which ones are to count as the intuition of the folk? Is it just the majority's intuition? And what happens when we have contradicting majorities in different cultural or social groups, like in Weinberg et al. 2001, and Nichols et al. 2003? Are they both equally privileged or do we have to pick one and how are we supposed to do this? Experimentalists show that folk intuitions are never unanimous. Alternative world-views exist. Thus they can no longer overlook the problem of an epistemic criterion.

Experimentalists will have to take a clear stand on those problems. $\mathrm{X} \Phi$ started out by recording intuitions. But the moment they tried to use those intuitions to advance philosophical theories, problems arise. Those problems may be even worse than those TAP had to face. For traditionalists accompanied their practice with a certain metaphilosophical view suggesting why and how those pre-theoretical intuitions are useful. Moderate experimentalists, on the other hand, have helped challenge all claims made by TAP, while keeping the same commitment to the appeal to intuitions.

${ }^{13}$ Apart from the free-will debate (for example, Nichols 2004; Nahmias et al. 2005, 2008; Nahmias 2006; Turner and Nahmias 2006) mentioned above, see also the intentional action debate (Knobe 2003; Mele 2003; Nadelhoffer 2005; Knobe 2006; Phelan and Sarkissian 2008). 


\section{Conclusion}

Experimentalists manage to collect intuitions better than armchair reflection. Their studies are very interesting insofar as they inform us what the folk believe and why. Also, whenever those studies are used to criticize the philosophical habit of appealing to intuition, they have managed a real shock. Radical experimental studies support theoretical arguments against TAP and show vividly the defects of relying on intuition as evidence. Still, when moderate experimentalists try to justify (or even to imply) how such studies are relevant to philosophy, problems arise.

It is far from clear that commonsensical intuitions are the source of philosophical problems. Experimentalists' studies show that the folk do not recognize any problem where philosophers do in fact acknowledge one. Yet, even if common sense was the source of philosophical worries, this would hardly entail that common sense can help answering those worries. However, for the sake of argument, let's assume that the folk could help addressing such problems. Even so, it is hard to see how the folk help when forced to vote for or against philosophical theories, which they are not even aware of. It seems that philosophers, once again, have found a new way to impose their doctrines on common sense. They use empirical studies to collect intuitions; and then they force their own philosophical views on the "pre-theoretical intuitions" of the folk.

Such a practice is incoherent when it comes from experimentalists. Traditionalists employ a conception of philosophy that accords with their method. They think philosophy is a strictly conceptual investigation. They defend reasoning by appealing to intuition because they think intuitions can help unravel conceptual rules. They insist we all share the same rules. Some even claim one can only use common sense to dissolve philosophical worries, not to address them. Even though such a conception of philosophy can be contested, it is in line with their method (Gutting 1998).

Experimentalists, however, would share neither claim. And still, many imply that intuitions can be utilized to advance theoretical theses. They have shown, nevertheless, that intuitions do not arise from conceptual rules alone. Cultural and/or socio-economic background, previous knowledge, the classes one has attended, the narrative of the questionnaire-story, etc., influence our intuitions. None of those factors are treated as theoretically reliable and all can be manipulated. Besides, since intuitions rely on so many factors, they are never unanimous. And if intuitions vary, we desperately need some 
criterion to decide which, if any, we can use. Experimentalists have challenged TAP's theoretical commitments while insisting on using folk intuitions.

The so-called moderate experimentalists then remain stuck in a controversy. One the one hand, they have vividly shown how untrustworthy intuition is. On the other, they depend all their theorizing on intuitions. ${ }^{14}$

\section{REFERENCES}

Alexander, J. and J.M. Weinberg, 2007, "Analytic Epistemology and Experimental Philosophy", Philosophy Compass, vol. 2, no. 1, pp. 5680.

Austin, J.L.,1964, Sense and Sensibilia, Oxford University Press, Oxford. —, 1961, Philosophical Papers, Oxford University Press, Oxford.

Bealer, G., 2004, "The Origins of Modal Error", Dialectica, vol. 58, pp. 1142.

—_ 1998, "Intuition and the Autonomy of Philosophy", in DePaul and Ramsey 1998, pp. 201-240.

—_ 1996, "On the Possibility of Philosophical Knowledge", Noûs, vol. 30, no. 10, pp. 1-34.

Bennett, M.R. and P.M.S. Hacker, 2003, Philosophical Foundations of Neuroscience, Blackwell, Malden.

Bishop M.A. and J.D. Trout, 2005, Epistemology and the Psychology of Human Judgement, Oxford University Press, New York.

Churchland, P.M., 1989, "Folk Psychology and the Explanation of Human Behavior", Philosophical Perspectives, vol. 3, pp. 225-241.

- 1986, "On the Continuity of Science and Philosophy", Mind and Language, vol. 1, pp. 5-14.

Cummins, R., 1998, "Reflection on Reflective Equilibrium", in DePaul and Ramsey 1998, pp. 113-128.

Dennett, D.C., 2006, Sweet Dreams, The MIT Press, Cambridge, Mass. — 1991, Consciousness Explained, Little Brown, Boston/New York.

DePaul, M.R. and W. Ramsey (eds.), 1998, Rethinking Intuition, Rowman and Littlefield, Oxford/New York,

Ekstrom, L.W., 2002, "Libertarianism and Frankfurt-Style Cases" in R. Kane (ed.), The Oxford Handbook of Free Will, Oxford University Press, New York, pp. 309-322.

Fodor, J., 1964, "On Knowing What We Would Say", Philosophical Review, vol. 73, pp. 198-212.

${ }^{14}$ I would like to thank IKY (the State Scholarships Foundation of Greece) for supporting this research. I would also like to thank Professors Peter Machamer and Stelios Virvidakis for their useful comments on earlier versions of this paper. 
Gasparatou, R., 2010, "Folk Intuitions, Science-Fiction and Philosophy", Journal of Cognition and Culture, vol. 10, nos. 3-4 (forthcoming).

, 2009, "High Standard Epistemology and the Appeal to Intuition", Filozofia, vol. 64, no. 7, pp. 680-692.

—_, 2008, “Armchair versus Questionnaire Polled Intuitions: Intuitions Nevertheless", The Reasoner, vol. 2, no. 11, pp. 7-9.

Gettier, E.L., 2000, "Is Justified True Belief Knowledge?", in S. Bernecker and F. Dretske (eds.), Knowledge, Oxford University Press, Oxford, pp. 13-15.

Gopnik A. and E. Schwitzgebel, 1998, "Whose Concepts Are They, Anyway?", in DePaul and Ramsey 1998, pp. 75-94.

Gutting, G., 1998, "Rethinking Intuition: A Historical and Metaphilosophical Introduction", in DePaul and Ramsey 1998, pp. 3-16.

Haack, S., 1974, Deviant Logic, Cambridge University Press, London/New York.

Haidt I., S. Koller, and M. Dias, 1993, “Affect, Culture and Morality”, The Journal of Personality and Social Psychology, vol. 65, no. 4, pp. 613628.

Howard, J.W. and Dawes, R., 1976, "Linear Prediction of Marital Happiness", Personality and Social Psychology Bulletin, vol. 2, no. 4, pp. $478-480$.

Jackman, H., 2009, "Semantic Intuitions, Conceptual Analysis and CrossCultural Variation”, Philosophical Studies, vol. 146, no. 2, pp. 159-177.

Jackson, F., 1998, From Metaphysics to Ethics: A Defence of Conceptual Analysis, Oxford University Press, Oxford.

—_, 1982, "Epiphenomenal Qualia", Philosophical Quarterly, vol. 32, pp. 127-139.

Kane, R., 1999, "Responsibility, Luck and Chance: Reflections on Free Will and Indeterminism", Journal of Philosophy, vol. 96, no. 5, pp. 217-240.

Kauppinen, A., 2007, "The Rise and Fall of Experimental Philosophy", Philosophical Explorations, vol. 10, no. 2, pp. 97-118.

Kitcher, P., 1983, The Nature of Mathematical Knowledge, Oxford University Press, New York.

Knobe, J., 2006, "The Concept of Intentional Action", Philosophical Studies, vol. 130, no. 2, pp. 203-231.

—_, 2003, "Intentional Action and Side Effects in Ordinary Language", Analysis, vol. 63, no. 279, pp. 190-194.

Knobe, J. and S. Nichols, 2008a, "An Experimental Philosophy Manifesto", in Knobe and Nichols 2008b, pp. 3-17.

- (eds.), 2008b, Experimental Philosophy, Oxford University Press, New York.

Kripke, S., 1996, Naming and Necessity, Harvard University Press, Cambridge, Mass.

Liao, S.M., 2008, “A Defense of Intuitions”, Philosophical Studies, vol. 140, no. 2, pp. 248-262. 
Mele A., 2003, "Intentional Action: Controversies, Data, and Core Hypotheses", Philosophical Psychology, vol. 16, no. 2, pp. 325-340.

Nadelhoffer, T., 2005, "Skill, Luck, Control, and Intentional Action", Philosophical Psychology, vol. 18, no. 3, pp. 325-340.

Nadelhoffer, T. and E. Nahmias, 2007, "The Past and Future of Experimental Philosophy", Philosophical Explorations, vol. 10, no. 2, pp. 123-149.

Nahmias, E., 2006, "Folk Fears about Freedom and Responsibility: Determinism vs Reductionism", Journal of Cognition and Culture, vol. 6, no. 12, pp. 215-237.

Nahmias, E., S. Morris, T. Nadelhoffer and J. Turner, 2008, "Is Incompatibilism Intuitive?", in Knobe and Nichols 2008b, pp. 81-104.

—_, 2005, "Surveying Freedom: Folk Intuitions about Free Will and Moral Responsibility", Philosophical Psychology, vol. 18, no. 5, pp. 561584.

Nichols, S., 2004, "The Folk Psychology of Free Will: Fits and Starts", Mind and Language, vol. 19, no. 5, pp. 473-502.

Nichols, S. and J. Knobe, 2007, "Moral Responsibility and Determinism: The Cognitive Science of Folk Intuitions", Noûs, vol. 41, no. 4, pp. 663685.

Nichols, S., S. Stich, and J. Weinberg, 2003, "Metaskepticism: Meditations in Ethno-Epistemology", in S. Luper (ed.), The Skeptics: Contemporary Essays, Ashgate Press, Aldershot, pp. 227-247.

Nisbett, R., K. Peng, I. Choi and A. Norenzayan, 2001, "Culture and Systems of Thought", Psychological Review, vol. 108, pp. 291-310.

Phelan, M.P. and H. Sarkissian, 2008, "The Folk Strike Back; or Why Did You Do It Intentionally, Though It Was Bad and You Knew It", Philosophical Studies, vol. 138, pp. 291-298.

Pollock, J. and J. Cruz, 1999, Contemporary Theories of Knowledge, Roman and Littlefield, Lanham.

Putnam, H., 1962, "The Analytic and the Synthetic", in H. Feigl and G. Maxwell (eds.), Minnesota Studies in the Philosophy of Science, University of Minnesota Press, Minneapolis, pp. 358-397.

Quine, W.V.O., 1953, "Two Dogmas of Empiricism", reprinted in W.V.O. Quine, 1980, From a Logical Point of View, Harvard University Press, Cambridge Mass, pp. 20-46.

Ramsey, W., 1998, "Prototypes and Conceptual Analysis", in DePaul and Ramsey 1998, pp. 161-178.

Sosa, E., 2008, "A Defense of the Use of Intuitions in Philosophy", in M. Bishop and D. Murphy (eds.), Stich and His Critics, Blackwell, Oxford, pp. 101-112.

- 2007, "Experimental Philosophy and Philosophical Intuition", Philosophical Studies, vol. 132, pp. 99-107. 647. 
Stich S., 1998, "Reflective Equilibrium, Analytic Epistemology and the Problem of Cognitive Diversity", in DePaul and Ramsey 1998, pp. 257271.

— 1990, The Fragmentation of Reason, Cambridge University Press, Cambridge.

Strawson, G., 1986, Freedom and Belief, Oxford University Press, Oxford.

Stroud, B., 2000, Understanding Human Knowledge, Oxford University Press, Oxford.

Swain, S., J. Alexander and J. Weinberg, 2006, "The Instability of Philosophical Intuitions: Running Hot and Cold on Truetemp", in The 32nd Annual Meeting of the Society for Philosophy and Psychology, Washington University, St. Louis, June 2006: <http://dingo.sbs.arizona.edu/ $\sim$ snichols/courses/saw.pdf $>[07 / 04 / 2010]$

Turner, J. and E. Nahmias, 2006, "Are the Folk Agent-Causationists?", Mind and Language, vol. 21, no. 4, pp. 597-609.

Weinberg, J., S. Nichols and J. Stich, 2001, "Normativity and Epistemic Intuitions", Philosophical Topics, vol. 29, pp. 429-460.

Williamson, T., 2004, "Philosophical 'Intuitions' and Scepticism about Judgments", Dialectica, vol. 58, no. 1, pp. 109-155.

Wittgenstein, L., 1958, Philosophical Investigations, trans. G.E.M. Anscombe, Blackwell, Oxford.

Received: March 17, 2009; revised: February 4, 2010; accepted: February 17, 2010. 